\title{
ASSESSMENT OF DIFFERENT UNMANNED AERIAL VEHICLE SYSTEM FOR PRODUCTION OF PHOTOGRAMMERTY PRODUCTS
}

\author{
M. H. M. Room, A. Ahmad and M. A. Rosly \\ Geoinformation, Faculty Built Environment and Surveying. Universiti Teknologi Malaysia, 81310 Johor Bahru, Johor, Malaysia \\ mdhafisroom88@gmail.com; anuarahmad@utm.my \& madlysalaf@gmail.com
}

KEY WORDS: UAV, Photogrammetry, LIDAR, RTK, Accuracy

\begin{abstract}
:
The demand of aerial photogrammetry has increased recently especially after the development of unmanned aerial vehicle system. This study explores the use of different UAV systems which comprised of conventional UAV, UAV RTK and UAV Lidar systems. This study also comprises of three experiments. The first experiment involved the mapping of Lingkaran Ilmu, UTM by using fixed wing Ebee UAV with 20megapixel digital camera. This first experiment used conventional UAV. The second experiment involved the fixed wing Ebee UAV equipped with real time kinematic (RTK) system on-board for mapping the study area. The last experiment is the used of octacopter UAV equipped with Riegl Lidar system for mapping the study area. The study area for all experiments is located in Lingkaran Ilmu of main campus Universiti Teknologi Malaysia, Johor Bahru, Johor, Malaysia. Ebee UAV and Ebee RTK UAV are flown in autonomous mode at 200 meters altitude. Both systems are used to capture high resolution aerial photo of the study area. Riegl UAV Lidar system is flown at 100 meter altitude for capture high resolution and point cloud data. GPS rapid static method was used for establishing ground control points (GCP) and check point (CP) in the study area. Three different GCP configuration was applied in geometry correction. Meanwhile, CPs is used for accuracy assessment where RMSE equation was employed. The 15CGP configuration produce more accurate result compared to another. Where, the planimetric RMSE values of Ebee UAV, Ebee RTK UAV and Riegl UAV Lidar are $0.21 \mathrm{~m}, 0.09 \mathrm{~m}$ and $0.15 \mathrm{~m}$ respectively. For height RMSE values for Ebbe, Ebee RTK and Octacopter Lidar are $0.34 \mathrm{~m}, 0.13 \mathrm{~m}$ and $0.07 \mathrm{~m}$ respectively. In conclusion, Ebee RTK UAV is identified as a system that can produce an accurate digital orthophoto compared to other systems while Riegl UAV Lidar system can produce highest accurate DEM and DTM compared to other systems in 15GCP configuration.
\end{abstract}

\section{INTRODUCTION}

\subsection{Unmanned Aerial Vehicle (UAV)}

Unmanned aerial vehicle (UAV) is also known as drone. It is an aircraft that does not require a pilot to operate it. The UAV has two variants: whether operated by remote control, or freely flown based on aviation plans that have been initially programmed using a tough dynamic automation system. (Romano and Utomo, 2015) At present, most UAVs can carry out surveillance missions and attacks. UAVs are also increasingly being used for public use, such as extinguishing fires, monitoring, inspection, surveying, mapping and many more applications. UAV is often used in missions, "dirty, dangerous and dull (3D)" missions.

The performance of UAV has improved from year to year. This development has provides wider opportunities within the photogrammetry field in obtaining digital images for large scale map production. The concept of UAV is similar to the manned aircraft but it requires professional personnel to handle the UAV from the ground control station (Tahar et. al., 2015). Aerial image is the most reliable data for mapping. It shows the images of the actual situation and the information of the ground which can be easily interpreted. Previously conventional aerial photographs or images are taken from an aircraft. However, aircraft required huge cost, time and manpower. For UAV, it can be handled by one person to operate the remote control and also cost efficient. The design, research and production of UAV platform are suitable in aerial photogrammetry. There are two types of UAV which are known as fixed wing and rotory wing.
Fixed wing needs more time to stabilize before it capture aerial photograph of the ground. Various types of fixed wing have been produced in accordance to its specific application or needs. Rotory wing is more stable and it is able to capture images easily. Rotory wing can be divided into two types which are single rotor (helicopter) and multi-rotor. It allows remote control UAV to be utilized for environment and urban mapping. Today, UAV has been widely used for mapping purposes. UAV can capture aerial images from certain height which depend on the size and shape. UAV system has become more popular in digital photogrammetry field due to several advantages compared to manned aircraft. UAV can fly with low altitude and uses small format digital camera for covering small area.

Therefore, the UAV is able to capture high resolution and clear images where aircraft or satellite is unable to provide clear image from very high altitude. The demands of aerial photogrammetry have also increased especially after the development of design, research and production of UAV platform. UAV has been widely used in various applications such as mapping, farming, quarry, archaeology, agriculture and many more. Recently, there are many systems of UAV have been created to support many applications in various discipline. Today, Light detection and range (LIDAR) designed and integrated with UAV system for producing an accurate point cloud data in close range location. Other than that UAV is able to produce an accurate topographic map without required ground control point (GCP) established on the ground. Today, UAV is integrated with GPS RTK system on-board and available in the market to produce high accurate topography map. 


\subsection{Photogrammetry}

Photogrammetry is the art, science and technology which involve several processes of physical object or certain areas in order to acquire information of the features of the earth surface (Udin et. al., 2012). Apart from that, it is an art because obtaining reliable measurements required certain skills, techniques and the decision need to be made by an individual. It is also a form of science and technology because it obtaining a images and transforms it via technology into significant output (Manyoky et. al., 2012). This technology can be used to measure, document or monitor almost anything that is detectable within the photograph.

Photographs or images used for photogrammetry can be derived from a special metric camera, a normal camera or digital sensor. The images can be recorded from a device mounted on a satellite, on an aircraft or on a tripod which set up on the ground. Modern photogrammetry includes image sources and image forms. The final product of the photogrammetric process can be coordinated or georeferenced value of individual points, a graphic representation of the ground surface such as topographic map or orthophoto. Basically, photogrammetry is widely used in produce topographic map, site planning, earthwork, volume calculation, DEM and orthophotography (Darwin et. al., 2014).

As mentioned before, UAV technology can be used in various discipline as well in photogrammetry discipline. This situation causes to the introduction of UAV Photogrammetry. This term was popular by Eisenbeiß in 2009. UAV Photogrammetry can be defined as a low cost technique for captured aerial photographs/aerial images for produce photogrammatry product comprises of orthophoto, dtm, dem, contour line, 3D model and others. Basically, there are many factors contributed to the quality of photogrammetry products such as focal length, types of UAV system, number of GCP, flying height and many more. All of these factors will affected the accuracy of photogrammetry results. Therefore, the main aim of this study is to investigate and evaluate the capabilities of three different UAV system for producing photogrammtry products based on the different GCPs configuration. The three different UAV systems comprised of conventional UAV, Lidar system and RTK system.

\section{METHODOLOGY}

\subsection{Study Area}

The study area was conducted in Lingakaran Ilmu, Universiti Teknologi Malaysia (UTM) at Skudai, Johor, Malaysia. The Lingkaran Ilmu is located at coordinates 1.560542 Latitude and 103.637287 Longitude. The total area of Lingkaran Ilmu is about 60 hectare which comprises of buildings of faculties, administration and mosque. This study area has various shape of topography where certain place is hilly area and another place is flat area. This factor is suitable and good location to investigate the ability of UAV system and different types of sensor to produce an accurate photogrammetry product that has different shape of topography. The location of Lingkaran Ilmu is shown in Figure 1.

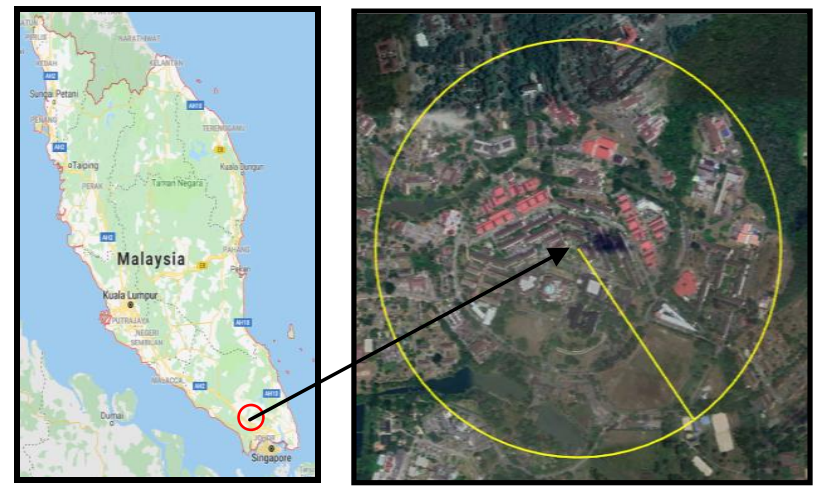

Figure 1. Location of Lingkaran Ilmu, UTM (Source: Google Earth)

\subsection{Data Acquisition}

There are three types of UAV used for capturing geospatial data in the study area. The data comprised of aerial photographs/images and point cloud. Camera calibration is carried out before the process of data collection begin. The main reason of camera calibration is to obtain the interior calibration parameters (c, xp, yp, k1, k2, k3, p1, p2, b1 and b2) because the digital camera attached under the UAV is nonmetric camera. The non-metric camera is a type of camera not specifically designed for mapping purpose, therefore its' interior calibration parameters are unstable and need to be determined.

Ebee, Ebee RTK and Riegl Lidar are three systems of UAV were used for capturing aerial photograhs/images and point cloud data. Specification of each system is shown in Table 1. Before commencing data collection, several parameters need to be clarified such as flying height, coverage of the study area, focal length, scale and percentage of end lap and side lap. All of these parameters were set in the mission planning software. In this study, all three different UAV systems were flown in different date due to the weather issue.

Table 1. Specification of UAV systems used for data collection

\begin{tabular}{|c|c|}
\hline \multicolumn{2}{|c|}{ Ebee UAV } \\
\hline Sensor & 20 MP digital camera \\
\hline Type & Fixed wing \\
\hline Endurance & Max 50 minutes \\
\hline $\begin{array}{c}\text { Absolute horizontal/vertical } \\
\text { accuracy (w/GCPs) }\end{array}$ & Down to $3 \mathrm{~cm} / 5 \mathrm{~cm}$ \\
\hline GSD & $1.5 \mathrm{~cm} /$ pixel \\
\hline \multicolumn{2}{|c|}{ Ebee RTK UAV } \\
\hline Sensor & 20 MP digital camera \\
\hline Type & Fixed wing \\
\hline Endurance & Max 90 minutes \\
\hline $\begin{array}{c}\text { Absolute horizontal/vertical } \\
\text { accuracy (w/GCPs) }\end{array}$ & Down to $3 \mathrm{~cm}$ (1.2 in) \\
\hline GSD & $2.5 \mathrm{~cm} / \mathrm{pixel}$ \\
\hline System & $\begin{array}{c}\text { Real Time Kinematic on } \\
\text { board }\end{array}$ \\
\hline \multicolumn{2}{|c|}{ Riegl UAV Lidar } \\
\hline Sensor & $\begin{array}{c}\text { Lidar VUX-1UAV and } 20 \\
\text { MP digital camera }\end{array}$ \\
\hline Type & Octacopter (8 rotor) \\
\hline Endurance & 15 minutes \\
\hline Accuracy/Precision & $10 \mathrm{~mm} / 5 \mathrm{~mm}$ \\
\hline Range & $3 \mathrm{~m}$ to $920 \mathrm{~m}^{2}$ \\
\hline Laser Pulse Repetition Rate & up to $550 \mathrm{kHz}$ \\
\hline
\end{tabular}


However, each UAV was flown in same condition where all UAV systems used same setting in mission planning software. Ebee UAV is equipped with $20 \mathrm{MP}$ digital camera was flown at 200 meters flying height with 70 percent end land and 80 percent side lap. This mission is able to capture about 800 high resolution aerial photographs of the study area. Meanwhile Ebee UAV integrated with RTK system on-board and equipped with $20 \mathrm{MP}$ digital camera is also flown with same flying height and percentage of side land and end lap.

However, Riegl UAV integrated with Lidar system and $20 \mathrm{MP}$ digital camera was flown at 100 meters with same percentage of side lap and end lap. The main reason the Riegl UAV Lidar flown at different flying height with others UAV because it only able to fly maximum 100 meters flying height due to the limitation of battery power. This mission able to capture about 1000 aerial photo and point cloud data. Later, the data obtained from UAV system were used in the processing phase using photogrammetry and lidar software.

The GCPs were collected using GPS observation using rapid static GPS technique. This technique can provide the position information that include Northing, Easting, and Elevation (X, $\mathrm{Y}$, and $\mathrm{Z}$ ) with the post processing by using the Trimble Total Control (TTC) software that gives accuracy at 1 to 10 centimetre level. The establishment of GCPs is very important in maintaining the precious and accuracy of photogrammetric products.

Figure 2 depicts the distribution of GCPs and CPs measured by using the rapid static technique. The coordinates obtained after processing are in Geocentric Datum of Malaysia (GDM2000). It needs to be converted to RSO using GDTS software. There are 25 points are successful established in the study area. Where, 15 points are used as GCPs and 10 points are used as CPs. GCP is used for determination of exterior parameters which include three spatial location of the camera position in space and three rotational parameters. The GCP is also used to link between the tie points and reference coordinate system used. Meanwhile, $\mathrm{CP}$ is used for check on the accuracy assessment of photogrammetric result.

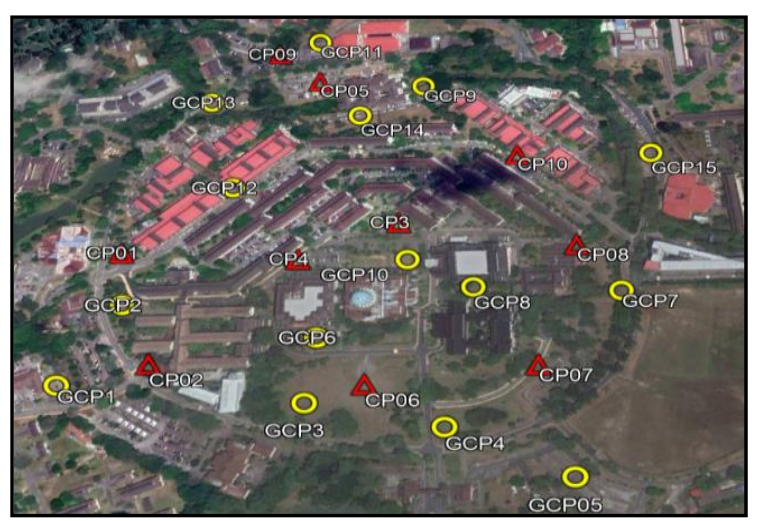

Figure 2: Location of GCPs (yellow circle) and CPs (red triangle) in the study area.
Each point was observed within 35 minutes into 45 minutes and height instrument at each point was measured. Theoretically, longer observation can produce more accurate result. In this study, observation of 35 into 45 minutes is enough for GPS observation because the location of each point is quite close to one another. The target made of plastic with dimension 1 meter length and 1 meter width is used as a marker to represents as GCPs and CPs on the digital orthophoto. The X symbol are printed on the top of the target to make sure the centre of the target is easily identified on the image during geometric correction and accuracy assessment.

\subsection{Data Processing}

All aerial photographs/images taken using digital camera and UAV system were processed using photogrammetry software known as Agisoft Metashape Profesional. The process comprised of interior orientation, which requires the camera calibration parameter and exterior orientation which require the registration of GCPs and auto generation of tie points. Basically, the processing of generating mapping product using photogrammetry software comprised four main steps. First, the location of aerial photographs is estimated based on the coordinate system extracted from camera digital. Then, a sparse point cloud model is generated. After that, the geometry and location of sparse point cloud model are corrected by referring to the information obtained from GCPs for producing an accurate dense cloud model.

In this step, the dense cloud model was processed based on three different GCP configuration. Where, the different number of GCP was used during image processing in order to investigate the effect of number of GCP against the quality of photogrammetric product. These three different GCP configuration which are $5 \mathrm{GCP}, 10 \mathrm{GCP}$ and $15 \mathrm{GCP}$. At the end, photogrammetry product such as digital orthophoto, DEM and 3D model are obtained. Meanwhile, point cloud was process using LIDAR 360 software. Unwanted point cloud model is removed using specific filter to produce dense cloud model. After that, DEM, DTM, orthophoto and 3D model are produced. Figure 3 shows the general flow chart of methodology.

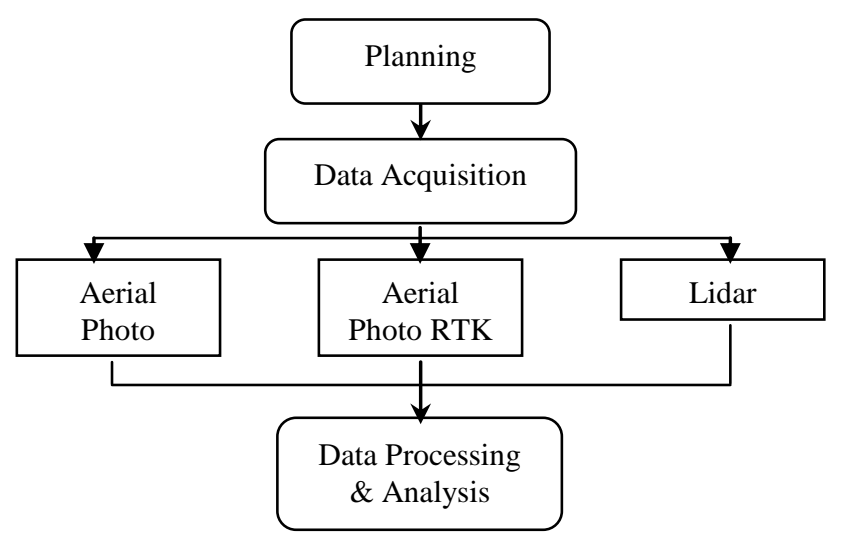

Figure 3. Flowchart of methodology in this study 


\section{RESULTS AND ANALYSIS}

\subsection{Results}

The results of this study comprised of digital orthophoto, DEM, DTM and 3D model. All the UAV systems are able to generate digital orthophoto and DEM meanwhile Riegl UAV Lidar system is able to produce DTM and 3D model for this study. The results are shown in Figure 4 until Figure 7.

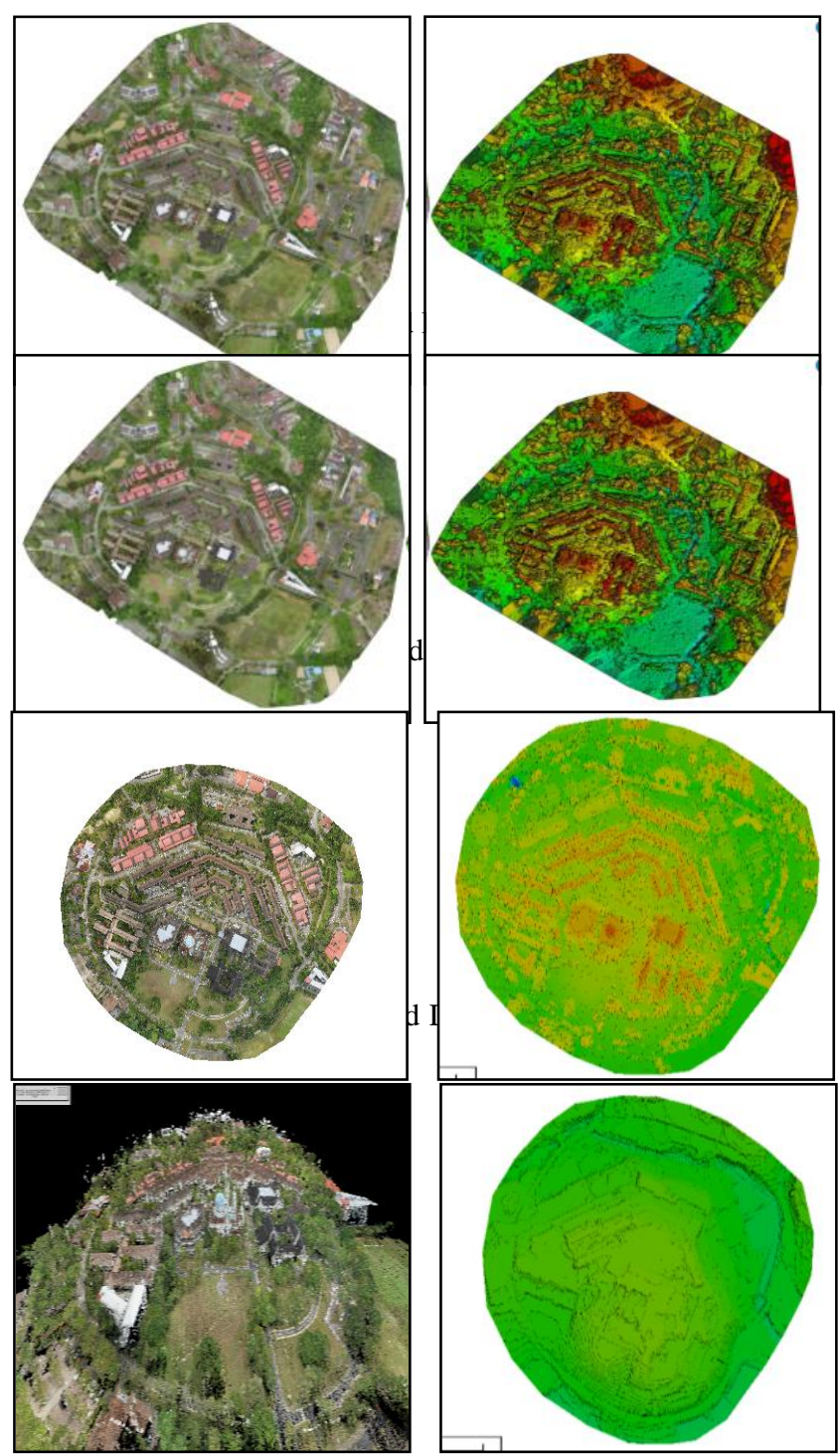

Figure 7. 3D Model (Left) and DTM (Right) from Riegl UAV Lidar

Based on Figure 4 until Figure 7, all UAV systems used in this study are successfully able produce photogrammetry products. Ebee UAV, Ebee RTK UAV and Riegl UAV Lidar are respectively capable to produce orthophoto and DEM. In this study, Riegl UAV Lidar was used to produce another product which are DTM and 3D model as shown in Figure 7. These products were produced through processing phase by using photogrammetry software and Lidar software. Residual Mean Square Error (RMSE) equation is used to evaluate the quality of all photogrammetry product obtained in this study. The RMSE equations are shown in equation 1 (planimetry) and equation 2 (height).
$\operatorname{RMSE}(\mathrm{X}, \mathrm{Y})= \pm \sqrt{\sum \frac{(x-x)^{2}+(y-g)^{2}}{\mathbb{N}}}$

$\operatorname{RMSE}(Z)= \pm \sqrt{\sum \frac{(Z-z)^{2}}{\mathbb{N}}}$

where,

$\mathrm{X}, \mathrm{Y}=$ Planimetry coordinate on the ground $(\mathrm{m})$.

$\mathrm{Z}=$ Height value on the ground $(\mathrm{m})$.

$\mathrm{x}, \mathrm{y}=$ Planimetry coordinate on the image $(\mathrm{m})$.

$\mathrm{z} \quad$ =Height value on the image (m).

$\mathrm{N} \quad=$ Number of check point $(\mathrm{CP})(\mathrm{m})$.

\subsection{Analysis}

Equations 1 and 2 were used to evaluate the quality of quantitative analysis against photogrammetry products. Table 2 shows the RMSE value of each UAV system based on different GCP configuration. While, Figure 8 and Figure 9 are respectively shows the comparison of RMSE of planimetry and RMSE of height were obtained in accuracy assessment phase.

Table 2 describes the RMSE results based on different GCP configurations which are 15 GCP, 10 GCP and 5 GCP. These different configurations were applied into results obtained from all three different UAV systems. Based on Table 2, the smallest RMSE value for planimetry and height coordinate is $15 \mathrm{GCP}$ configuration compared to another configuration. Where, the RMSE value of planimetry range from $\pm 0.09 \mathrm{~m}$ into $\pm 0.21 \mathrm{~m}$ and the RMSE value of height is in between $\pm 0.07 \mathrm{~m}$ and \pm 0.34 $\mathrm{m}$. Apart from that, 10GCP configuration able to produce a better accuracy rather than 5GCP. In this case, the RMSE value of planimetry is $\pm 0.21 \mathrm{~m}$ into $\pm 0.30 \mathrm{~m}$ and the RMSE value of height is $\pm 0.15 \mathrm{~m}$ into $0.50 \mathrm{~m}$.

The range RMSE value of planimetry for $5 \mathrm{GCP}$ configuration is $\pm 0.30 \mathrm{~m}$ into $\pm 0.43 \mathrm{~m}$ while the range RMSE value of height is $\pm 0.21 \mathrm{~m}$ into $\pm 0.58 \mathrm{~m}$. This result proves the number of GCP is one the factor will affect the accuracy of photogrammetry products. Figure 8 and Figure 9 also describe the relationship between number of GCP used during image processing and RMSE value. Higher number of GCP used in image processing, the software able to identify and transform the model into more accurate projection based on location information derived from GCP coordinate. The model is projected into real world projection in order to obtain an accurate information. Basically, a better quality of results is represented by smaller value of RMSE.

Table 2: Accuracy assessment of UAV system in producing photogrammetry product

\begin{tabular}{|c|c|c|c|}
\hline $\begin{array}{c}\text { Number of } \\
\text { GCP }\end{array}$ & UAV System & \multicolumn{2}{|c|}{ RMSE (m) } \\
\cline { 3 - 4 } & & $\begin{array}{c}\text { Planimetry } \\
(\mathbf{m})\end{array}$ & $\begin{array}{c}\text { Height } \\
(\mathbf{m})\end{array}$ \\
\hline \multirow{7}{*}{15} & Ebee UAV & \pm 0.21 & \pm 0.34 \\
\cline { 2 - 4 } & $\begin{array}{c}\text { Ebee RTK } \\
\text { UAV }\end{array}$ & \pm 0.09 & \pm 0.13 \\
\cline { 2 - 4 } & $\begin{array}{c}\text { Riegl UAV } \\
\text { Lidar }\end{array}$ & \pm 0.15 & \pm 0.07 \\
\hline \multirow{7}{*}{10} & Ebee UAV & \pm 0.30 & \pm 0.50 \\
\cline { 2 - 4 } & $\begin{array}{c}\text { Ebee RTK } \\
\text { UAV }\end{array}$ & \pm 0.21 & \pm 0.27 \\
\cline { 2 - 4 } & $\begin{array}{c}\text { Riegl UAV } \\
\text { Lidar }\end{array}$ & \pm 0.26 & \pm 0.15 \\
\hline
\end{tabular}


The International Archives of the Photogrammetry, Remote Sensing and Spatial Information Sciences, Volume XLII-4/W16, 2019 6th International Conference on Geomatics and Geospatial Technology (GGT 2019), 1-3 October 2019, Kuala Lumpur, Malaysia

\begin{tabular}{|c|c|c|c|}
\hline 5 & Ebee UAV & \pm 0.43 & \pm 0.58 \\
\cline { 2 - 4 } & $\begin{array}{c}\text { Ebee RTK } \\
\text { UAV }\end{array}$ & \pm 0.30 & \pm 0.38 \\
\cline { 2 - 4 } & $\begin{array}{c}\text { Riegl UAV } \\
\text { Lidar }\end{array}$ & \pm 0.32 & \pm 0.21 \\
\hline
\end{tabular}

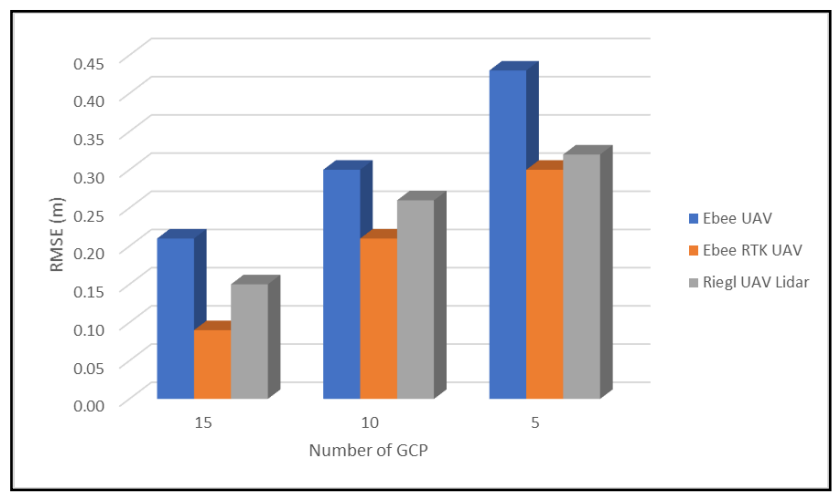

Figure 8. Graph shows the relationship between number of GCP and RMSE of Planimetry

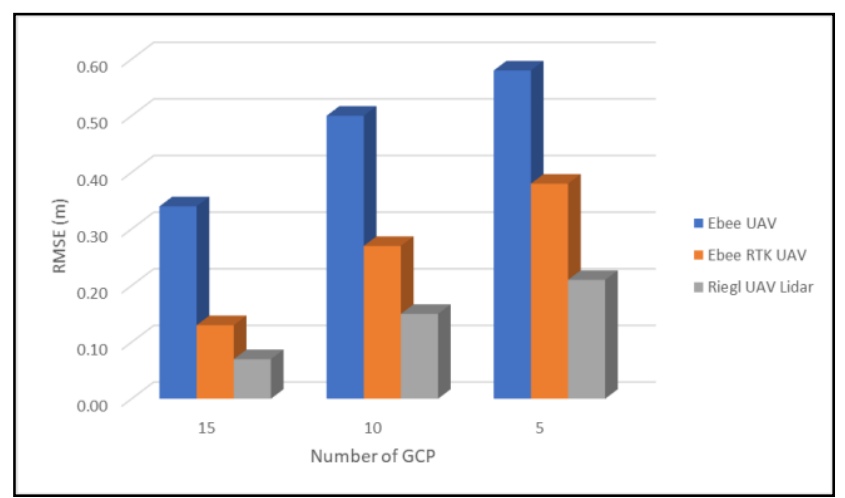

Figure 9. Graph shows the relationship between number of GCP and RMSE of Height

Among of the UAV system, Ebee RTK UAV is able to produce accurate digital orthophoto in all configuration with value between $\pm 0.09 \mathrm{~m}$ into $\pm 0.30 \mathrm{~m}$ compared to others system. This system is capable to generate an accurate digital orthophoto because Ebee RTK UAV is equipped with RTK GPS system on-board. RTK is the system designed to produce accurate location information in centimetre level. Riegl UAV Lidar can produce a better accuracy of digital orthophoto compared to Ebee UAV with RMSE value in between $\pm 0.15 \mathrm{~m}$ and $\pm 0.32 \mathrm{~m}$. This because Riegl UAV Lidar was flown much closer into the target with flight altitude $100 \mathrm{~m}$.

Both system equipped with $20 \mathrm{MP}$ of camera. The flight altitude will influence the image resolution and ground sampling distance (GSD). Where, the higher image resolution can be produced from lower flight altitude. In this study, aerial photo captured from Rigel UAV Lidar is higher image resolution compared to Ebee RTK. The higher image resolution helps in identify the centre of GCP and CP because the image is very clear. Meanwhile, Riegl UAV Lidar is successful produce more accurate DEM and DTM with RMSE $= \pm 0.07 \mathrm{~m}$ until $\pm 0.21 \mathrm{~m}$ compared to Ebee UAV and Ebee RTK UAV in all configuration. Lidar technology is already known capable to produce high accurate height information because the system uses laser pulse for scanning any features on the earth surface.

\section{CONCLUSION}

In conclusion, this study has proven that the UAV with different sensor system (conventional UAV, RTK system and Lidar) are able to produce photogrammetry product of the study area. Basically, these UAV systems provide the results with accuracy at centimetre level. Ebee RTK UAV are identified as a system that can produce an accurate digital orthophoto compared to other systems. Lidar system can produce highest accurate DEM/DTM compared to another system in this study. Apart from that, 15 GCP configuration can produce an accurate result compared to another configuration. It shows that the number of GCP also will effect the RMSE value and quality of photogrammetry products.

\section{ACKNOWLEDGEMENTS}

The authors sincerely acknowledge the Ministry of Education (MOE) and Universiti Teknologi Malaysia (UTM) for the funding this research through Zamalah Scholarship and Research University Grant (RUG) Q.J130000.2527.19H42.

\section{REFERENCES}

Darwin, N., Ahmad, A., and Akib, W. The potential of low altitude aerial data for large scale mapping. Jurnal Teknologi, 70 (2014), 5 .

Eisenbeiß, H. UAV photogrammetry. ETH Zurich Ph.D. Thesis, 2009.

Falkingham, P. L. Acquisition of high resolution threedimensional models using free, open-source, photogrammetric software. Palaeontologia Electronica, 15(1) (2011), 1-15.

Fazeli, H., Samadzadegan, F., and Dadrasjavan, F.Evaluating the potential of RTK-UAV for automatic point cloud generation in 3D rapid mapping. The International Archives of Photogrammetry, Remote Sensing and Spatial Information Sciences, 41 (2016), 221.

Fiorillo, F., Limongiello, M., and Fernández-Palacios, B. J. Testing GoPro for 3D model reconstruction in narrow spaces. Acta Imeko, 5(2) (2016), 64-70.

Jarzabek-Rychard, M., and Karpina, M. Quality analysis on 3D buidling models reconstructed from uav imagery. International Archives of the Photogrammetry, Remote Sensing and Spatial Information Sciences - ISPRS Archives, 2016 (2016), 11211126.

Jebur, A., Abed, F., and Mohammed, M. Assessing the performance of commercial Agisoft PhotoScan software to deliver reliable data for accurate 3D modelling. MATEC Web of Conferences, 162 (2018), 03022.

Manyoky, M., Theiler, P., Steudler, D., and Eisenbeiss, H. Unmanned Aerial Vehicle In Cadastral Applications. ISPRS International Archives of The Photogrammetry, Remote Sensing And Spatial Information Sciences, 3822 (2012), 57-62.

Rijsdijk, M., Hinsbergh, W., Witteveen, W., Buuren, G. H. M., Schakelaar, G. A., Poppinga and G.Ladiges, R. (2013). Unmanned aerial systems in the process of juridical verification 
of cadastral border. In Presentation at UAV-g Conference, Rostock University, Rostock, Germany.

Rokhmana, C. A., and Utomo, S. The Low-Cost UAV-Based Remote Sensing System Capabilities for Large Scale Cadaster Mapping. In IOP Conference Series: Earth and Environmental Science 47 (2016), 12005.

Sadikin, H., Andreas, H., and Prasetya Suherman Putra, A.. Land Parcel 3D Mapping Using Terrestrial Laser Scanning(TLS) Case study: Mutiara Beach, Jakarta, Indonesia. (2017)

Tahar, K. N. Multi rotor UAV at different altitudes for slope mapping studies. The International Archives of Photogrammetry, Remote Sensing and Spatial Information Sciences, 40(1) (2015), 9.

Udin, W. S., Hassan, A. F., Ahmad, A., and Tahar, K. N. Digital Terrain Model extraction using digital aerial imagery of unmanned aerial vehicle. In Signal Processing and its Applications (CSPA), 2012 IEEE 8th International Colloquium (2012) 272-275.

Wroc, M. K., and Sciences, L. Quality Analysis on 3D Buidling Models Reconstructed From Uav Imagery (2016),0-6.

Yanagi, H., and Chikatsu, H. Performance Evaluation Of 3d Modeling Software For Uav Photogrammetry. International Archives of the Photogrammetry, Remote Sensing \& Spatial Information Sciences, 41 (2016). 